\title{
Study on the Cooling Effect of Window Gardens
}

\author{
Jing Ren, Ming fang Tang, 1 \\ ${ }^{1}$ Faculty of Architecture and Urban Planning, Chongqing University, 400045 Chongqing, P.R. China
}

\begin{abstract}
Window gardens are known to provide a window view with psychological and physiological benefits, whether they can be used for passive cooling of buildings remains to be investigated. This paper aims to supplement the impact of window gardens on the thermal performance of windows, walls, and even indoor air temperatures, which previous research has ignored. A field experiment was conducted for two classrooms with integrated planting troughs outside the windows, with and without living plants. The indoor air temperature and the interior surface temperature of the two classrooms were measured on a typical hot summer day, with windows closed and air conditioners switched off. The results show that: Window garden with living plants can not only reduce the average temperature of the indoor air by $1.1{ }^{\circ} \mathrm{C}$, but also reduce the average temperature of the interior surface of the building envelope by $2.8{ }^{\circ} \mathrm{C}$, the reduction of interior surface temperature is more obvious, which is due to the formation of a cold bridge. Therefore, Window garden can improve the summer indoor thermal environment in hot summer and warm winter area in China. Keywords. Window gardens; Indoor air temperature; Interior surface temperature; Passive cooling
\end{abstract}

\section{Introduction}

Vertical greening systems (VGS) is one of the strategies to improve indoor comfort and reduce energy consumption, and also has many other benefits[1-7]. Window gardens are also VGS used to improve the greening rate of the building envelope and to provide people with pleasant window views. According to the research status, the research on the window garden mainly focuses on the design form and its effect on solar radiation[8-13]. In addition, people receive benefits from vegetation in window views, such as increased attentiveness and productivity, reduced stress and mental fatigue, and increased recovery rates in hospitals due to improved well-being[14-17]. Although window gardens are known to provide a window view with psychological and physiological benefits, whether they can be installed in buildings as shading systems and used for passive cooling remains to be investigated.

This paper aims to supplement the impact of window gardens on the thermal performance of windows, walls, and even indoor air temperatures, which previous engineering research has ignored. This study analysed the passive cooling of a window garden on two classrooms of a teaching building in Xiamen in a hotsummer and warm-winter area of China[18]. A field experiment was conducted for these two classrooms to have integrated planting troughs outside windows, with and without living plants. The detailed thermal performance of these two classrooms, such as the indoor air temperature, interior surface temperature was analyzed on a typical hot summer day.

\section{Methodology}

\subsection{Experimental site}

The experimental building is a mega-structure teaching building in Xiamen that is oriented to the south and receives no shelter from other facilities, and the floor plan is shown in Fig. 1(a). The teaching building contains 7 areas connected by a corridor: A, B, C, D, E, $\mathrm{F}$ and $\mathrm{G}$, among which $\mathrm{C}, \mathrm{D}, \mathrm{E}$ and $\mathrm{F}$ have the same structure, and the height of the building is five floors. The planting troughs of the window gardens were designed for attachment outside the building windows and were constructed synchronously with the teaching building to form integrated window gardens planting troughs with a unified layout in terms of pattern, colour and even plant configuration. Among the window planting troughs, only that in zone D has no plants and no irrigation. In this paper, the middle rooms on the fourth floor of $\mathrm{D}$ and $\mathrm{E}$ were used as the experimental objects to eliminate the thermal interference of the roof and walls at both ends (marks in Fig. 1(b) and 1(e)). The two classrooms had identical internal volumes $(12 \mathrm{~m} \times 8$ $\mathrm{m} \times 3.5 \mathrm{~m})$, as shown in Fig. 2. Each classroom was designed with two planting troughs of the same volume $(4.9 \mathrm{~m} \times 1.0 \mathrm{~m} \times 0.4 \mathrm{~m})$ that were integrated with the teaching building and filled with soil. Whether the planting trough contained plants was the only difference between the two classrooms. Therefore, for simplicity, "with plants" and "without plants" will be used to refer

\footnotetext{
* Corresponding author: 18740394222@163.com
} 
to the two rooms. In addition, the small shrubs (Aglaia duperreana) were approximately 0.6-0.8 m high (Fig. 2(c)) and irrigated by an automatic control irrigation equipment.

\subsection{Experimental setup}

The passive cooling of window gardens was experimentally evaluated on $16 / 07 / 2016$, and the whole day was sunny. The maximum outdoor air temperature was $32.9^{\circ} \mathrm{C}$, and the maximum global horizontal solar radiation was $1036 \mathrm{~W} / \mathrm{m}^{2}$, which represents the typical summer weather of Xiamen. The air conditioning was switched off throughout the day on 15/07/2016 and $16 / 07 / 2016$. The physical parameters measured included outdoor and indoor air temperature; solar radiation; and the interior surface temperature of the building envelope. Fig. 1 shows the location of temperature sensors ( $\mathrm{T}$ points) used to measure the outdoor air temperature, which were located in the corridor on the fourth floor. A solar radiation meter unobstructed at the top of the building was used to measure the solar radiation. Fig. 2 shows the location of the temperature sensors used to evaluate the indoor air temperature, and the indoor air temperature was averaged from the temperature measurements at points T1-T3. The interior surface temperature of the building envelope was measured by an infrared thermal imager, and the surface emissivity was set to 0.9 . All data were recorded at $1 \mathrm{~h}$ interval.

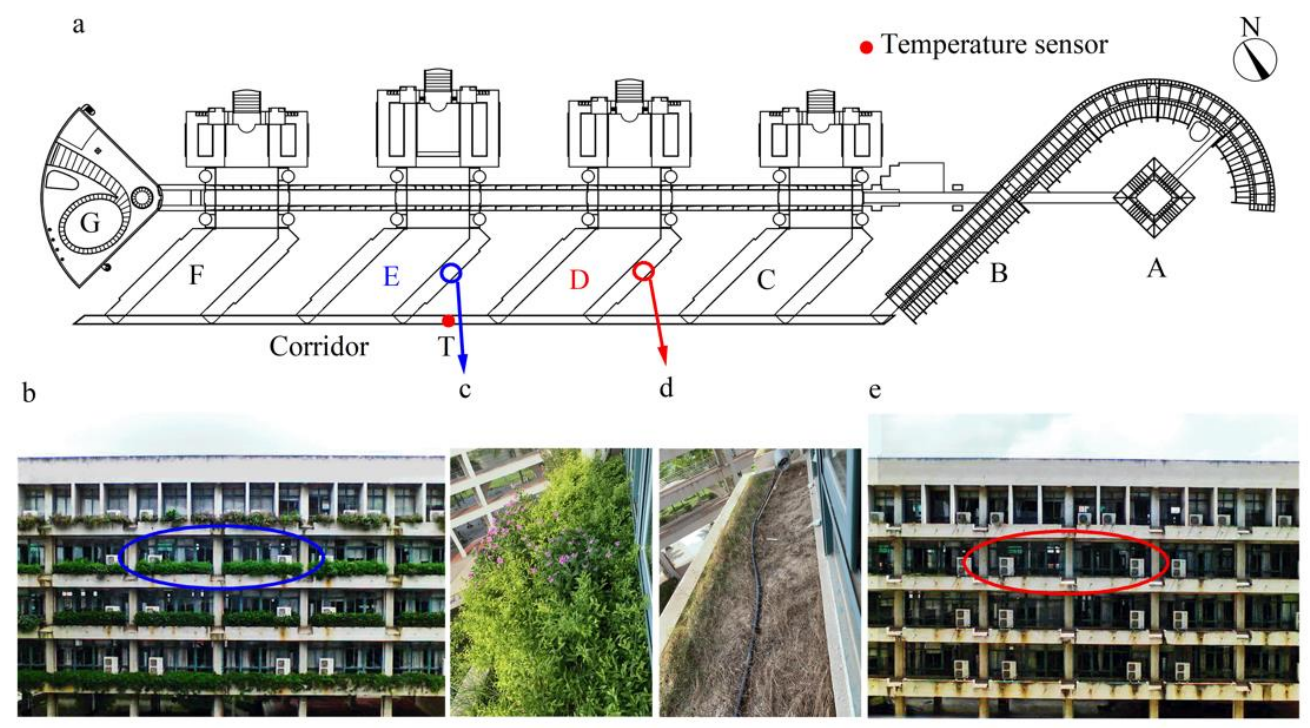

Fig. 1. (a) Floor plan of the mega-structure teaching building, (b) Facade of window gardens with plants, (c) Window planting rough with plants, (d) Window planting trough without plants, (e) Facade of window gardens without plants.
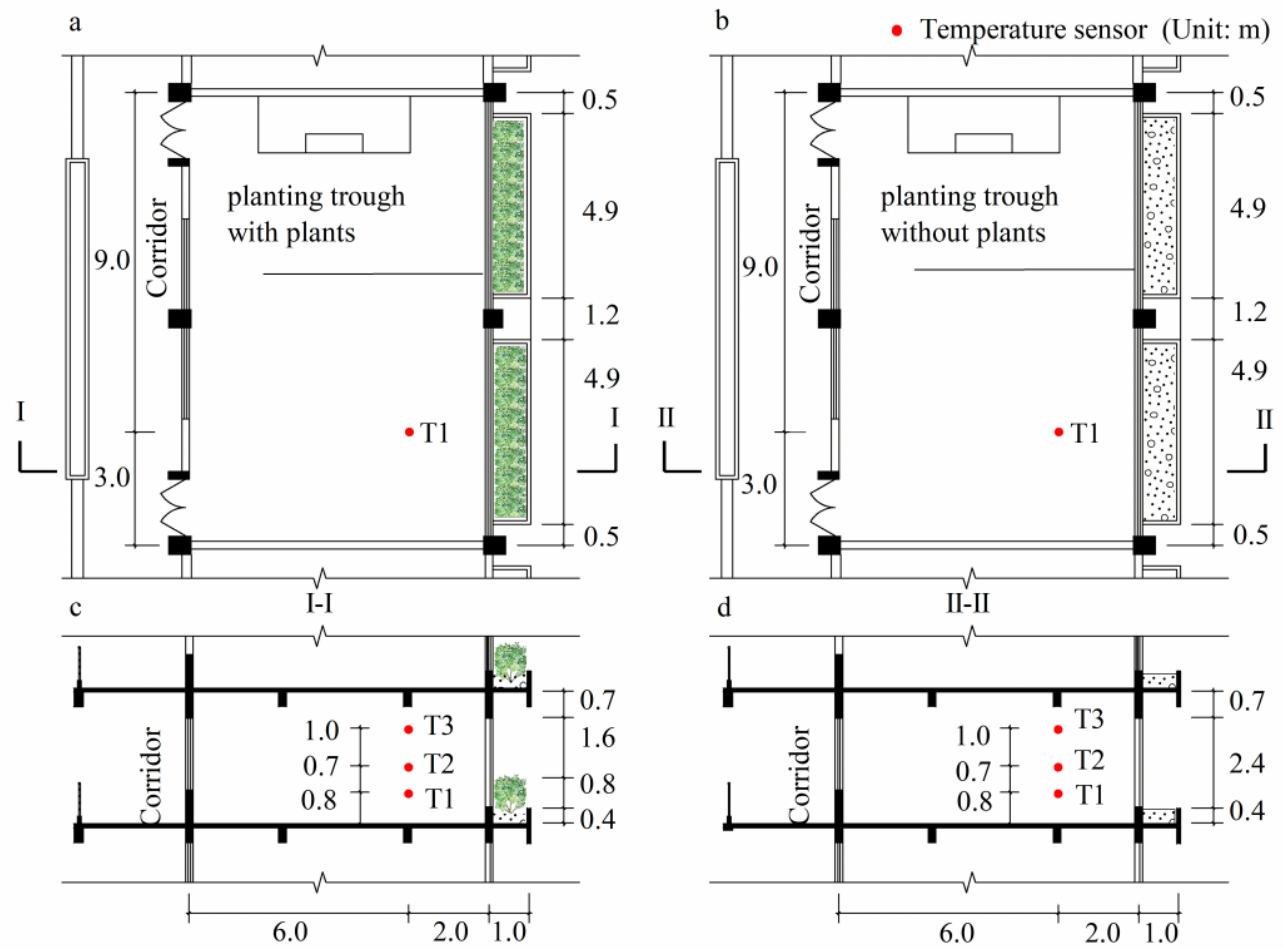

Fig. 2. (a) Flat sections of the classrooms with plants, (b) Flat sections of the classrooms without plants, (c) Profile section of I-I, (d) Profile section of II-II. 


\section{Results}

\subsection{Changes in indoor air temperature over time}

The changes in indoor air temperature over time are shown in Fig. 3. The average outdoor air temperature was $31.0^{\circ} \mathrm{C}$, the average indoor air temperature of the room with plants was $30.6^{\circ} \mathrm{C}$, which was $0.4^{\circ} \mathrm{C}$ lower than the outdoor air temperature. Additionally, the average indoor air temperature of the room without plants was $31.7^{\circ} \mathrm{C}$, which was $0.7^{\circ} \mathrm{C}$ higher than the outdoor air temperature. The indoor air temperature of the room with plants was lower than that of the room without plants by $1.1^{\circ} \mathrm{C}$. Therefore, the plants affected the indoor air temperature.

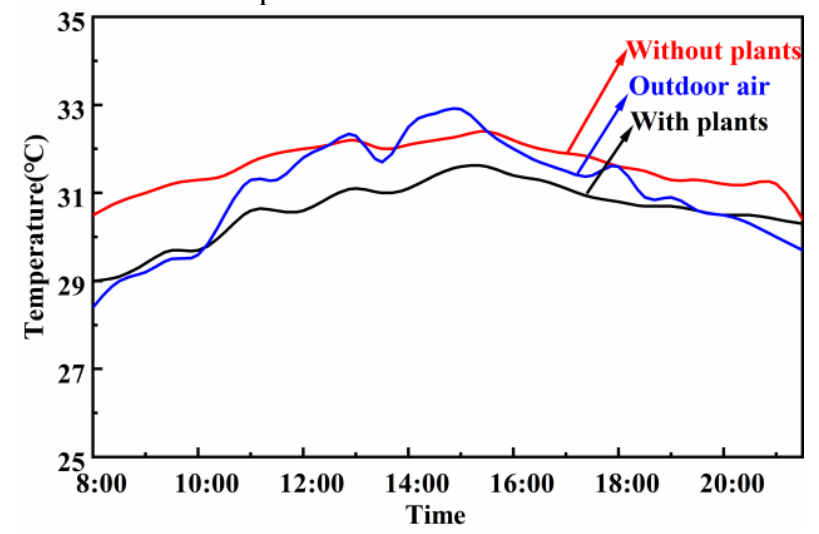

Fig. 3. Measured outdoor air temperature and indoor air temperature with and without living plants.

\subsection{Changes in interior surface temperature over time}

In this experiment, an infrared thermal imager was used to measure the interior surface temperature. Fig. 4 shows the thermal imaging of the interior surface temperature within one hour during the experiments. The thermal images were taken manually every hour from 8:00 to 18:00 on that day. By analysing the vertical linear temperature (line spanning heights from 0 to $3.2 \mathrm{~m}$ in Fig. 4), the variation of the interior surface temperature in a day was obtained. In the lower part of the windowpanes and on walls sheltered by the window gardens(height of $0-1.4 \mathrm{~m}$ ), the window gardens exhibited more significant cooling and a more variable range of the vertical temperature gradient than the envelope without plants. Thus, the effective height range of the cooling function was related to the height of the planting trough and the vegetation. The height of the small shrub selected in this paper is about 0.6-0.8 meters, which can be used for design reference.

To quantify the reduction in interior surface temperature, changes in the average temperature of the interior surfaces from 8:00 to 18:00 were determined, as shown in Fig. 5. For the envelope without plants, the average temperature of the interior surface was $32.6^{\circ} \mathrm{C}$, which was $0.9^{\circ} \mathrm{C}$ higher than the indoor air. For the envelope with plants, the average temperature of the interior surface was $29.8^{\circ} \mathrm{C}$, which was $0.8^{\circ} \mathrm{C}$ lower than that of the indoor air. The interior surface temperature was higher than the indoor air temperature only when the solar radiation reached its maximum. In addition, due to the drip irrigation of the plants between 8:00-10:00, the evaporation of soil moisture also played a role in cooling, resulting in the interior surface temperature reduction being more obvious. Moreover, the average temperature of the interior surface was $2.8^{\circ} \mathrm{C}$ lower than that of the envelope without plants. The interior surface temperature was lower than that of the envelope without plants, and the temperature difference between the two interior surfaces was more obvious, especially at the extremely high temperature in the afternoon.

Thus, the cooling mechanism of window gardens can be attributed to two aspects: (i) the shadows produced by the vegetation and trough-shaped containers; and (ii) cooling via vegetation transpiration and moistened soil evaporation.

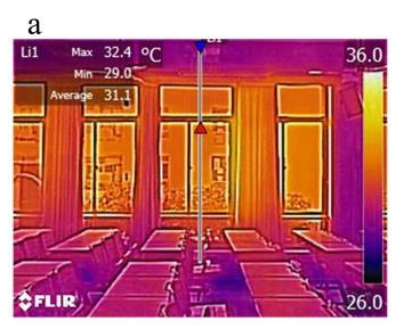

C
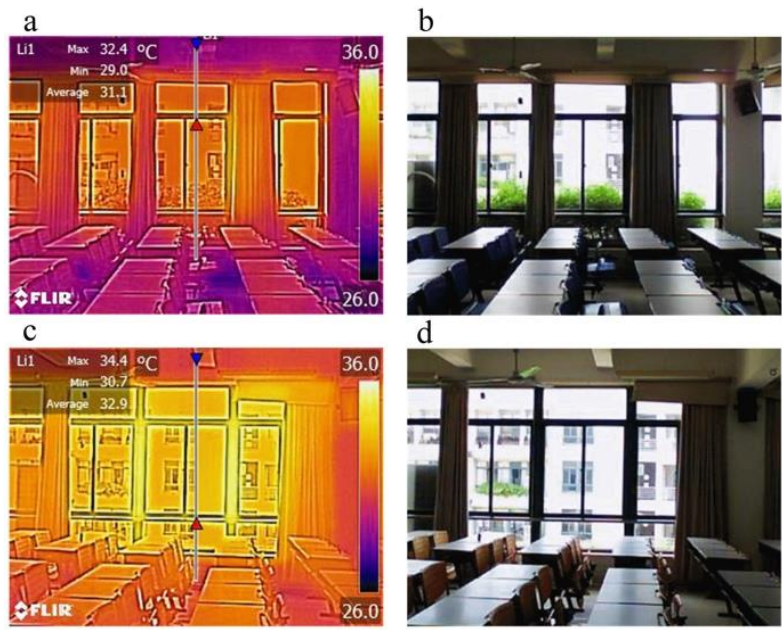

$\mathrm{d}$

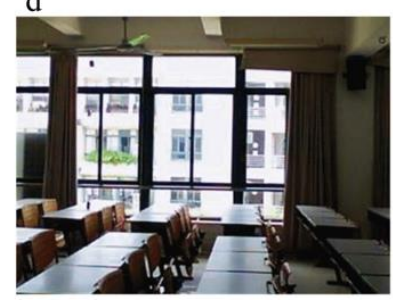

Fig. 4. (a) Thermal imaging of interior surface temperature with plants, (b) Original imaging of interior surface with plants, (c) Thermal imaging of interior surface temperature without plants, (d) Original imaging of interior surface without plants.

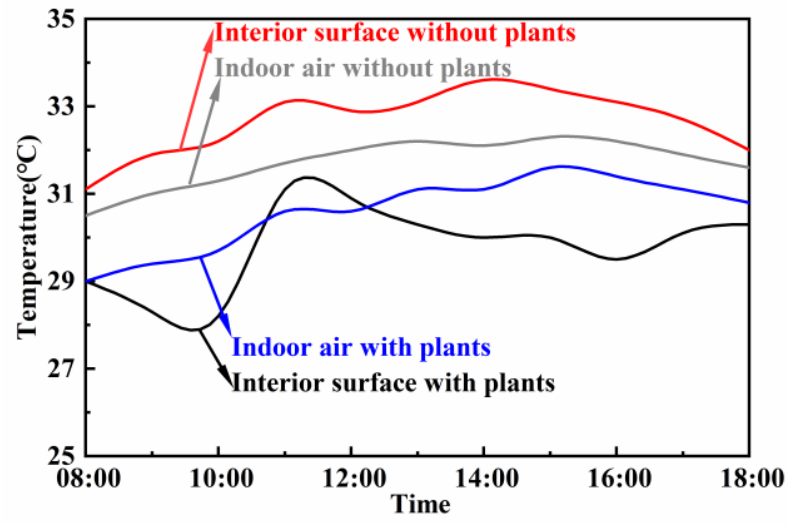

Fig. 5. Measured interior surface temperature and indoor air temperature with and without living plants.

\section{Conclusions}

This study analysed the passive cooling of a window garden on two classrooms of a teaching building in Xiamen in a hot-summer and warm-winter area of China, and the results show that: Window garden with living plants can not only reduce the average temperature

\footnotetext{
*Corresponding author: 18740394222@163.com
} 
of the indoor air by $1.1^{\circ} \mathrm{C}$, but also reduce the average temperature of the interior surface of the building envelope by $2.8{ }^{\circ} \mathrm{C}$, the reduction of interior surface temperature is more obvious, which is due to the formation of a cold bridge. All in all, the passive cooling of Window garden seems to be a significant argument supporting the idea of installing plants in the buildings as a shading system. In our next work, we plan to establish a numerical model and perform energy-saving experiments to further reveal the influence of different types and heights of plants on the interior surface temperature gradient of the building envelope.

This project was funded by the National Natural Science Foundation of the People's Republic of China (Grant No. 51678254). We express sincere thanks to Professor Maoyu Ran for his assistance in conducting the experiments.

\section{References}

1. M.J.S.E. Santamouris, Solar Energy, 103 (2014).

2. K. Perini, R.J.U.E. Raiteri, Urban Ecosystems 16(2013).

3. I. Susorova, P. Azimi, B. Stephens, Build Environ, 76 (2014).

4. K. Ip, M. Lam, A. Miller, Build Environ, 45(2010).

5. N.H. Wong, A.Y.K. Tan, P.Y. Tan, N.C. Wong, Energy Buildings, 41(2009).

6. S. Charoenkit, S. Yiemwattana. Build Environ, 105 (2016).

7. R.A. Bustami, M. Belusko, J. Ward, S. Beecham, Build Environ, 146 (2018).

8. Sun Jinkun. International Conference on Advances in Energy \& Environmental Science, 29(2015).

9. W.J. Stec, A.H.C. van Paassen, A. Maziarz, Energy Buildings, 37 (2005).

10. K. Ip, M. Lam, A. Miller. Build Environ, 45(2010).

11. N. Takayama, H. Yoshikoshi, H. Yamamoto. J Environ Eng-ASCE, 76 (2011).

12. Xing Zheng, Xiaodi Li, Chen Yue, Lingyun Wang. J Civil Eng \& Environ Eng, S1 (2013).

13. S.F. Larsen, C. Filippín, G. Lesino, Energy Procedia, 57 (2014).

14. A. Dravigne, T.M. Waliczek, R.D. Lineberger, J.M. Zajicek, Hortscience 43(2008).

15. R.S. Ulrich, Science 224 (1984).

16. C. Chen, Landscape Archit, University of Illinois at Urbana-Champaign, (2015).

17. D.Y. Li, W.C. Sullivan, Landscape and Urban Planning, 148 (2016).

18. MOHURD, China Building Industry Press, Beijing, (2016). 